\title{
Management and Surgical Outcome of Non Missile Penetrating Head Injuries at Assiut University Hospital: One Year Study
}

\author{
AHMED I. EL-GHERIANY, M.D.; ABD EL-HAKEEM ABD EL-SATTAR M.D.; \\ AHMED EL-SHANAWANY, M.D. and HAMADA M. RAMADAN, M.Sc.
}

The Department of Neurosurgery, Faculty of Medicine, Assiut University

\begin{abstract}
Background: Non missile Penetrating head injury (NPHI) is head trauma in which an object other than bullets breaches the cranium and dura matter. Although NPHI is less common than missile penetrating injuries, it's management represent major challenge to health care providers in general and neurosurgeons particularly as impacted object (weapon) poses some technical difficulties in the investigation and management of the victims.
\end{abstract}

Aim of the Study: Our study is based on analysis of clinical-radiological profile and outcome of patients of penetrating brain injuries.

Patients and Methods: This is a prospective hospital based study includes 6 patients with non missile penetrating head injuries admitted and managed at department of neurosurgery and trauma units of Assiut university hospital through one year from march 2015 to march 2016.

Results: The mean age was 17 years, and most patients were males. Most common clinical presentation was brain matter herniation with impacted object in victims skull in 5 $(83.3 \%)$ patients followed by decreased level of consciousness in $4(66.6 \%)$ patients. Fronto-Parietal lobe injury noted in 4 $(66.6 \%)$ patients followed by temporal lobe in $2(33.3 \%)$ patients. One patient died during the hospital stay. Patients discharged according to Glasgow outcome scale(GOS). Two patients were discharged in GOS-4 and three patients in GOS5. Seizure developed in two $(33.3 \%)$ patients.

Conclusion: Non missile Penetrating head injuries are most common in children and adolescents and occur more commonly in male. Most common presentation was brain matter herniation or CSF leak. Fronto-Parietal and temporal lobar injury are the most common injury sites with higher mortality in temporal lobe injuries.

Key Words: Penetrating - Non missile - Head injury - Assiut university.

\section{Introduction}

NON MISSILE Penetrating head injury (NPHI) is head trauma in which a projectile other than

Correspondence to: Dr. Ahmed I. El-Gheriany

The Department of Neurosurgery, Faculty of Medicine,

Assiut University bullets breaches the cranium and dura matter, usually caused by a foreign object with an impact velocity of less than 100 meter/second [1]. Traumatic brain injury is the result of energy being transferred from an object to the human skull and underlying brain. The penetrating object has kinetic energy that equals half of the projectile mass multiplied by square of its velocity $(\mathrm{kE}=1 / 2 \mathrm{mv} 2)$ which means that the projectile velocity has a greater influence than projectile mass. Unlike missile injuries non missile injuries by stabbing are largely restricted to the wound tract [2]. The reported high incidences of stab on left side of skull are probably due to right-handedness of the assailant. The most common injury site is the frontoparietal region [3]. Temporal stab wounds are more likely to demonstrate major neurological deficits due to thinness of the temporal bone and short distance to the deep vital brain and vascular structures [4].

NPHIs in children may initially appear trivial and are often missed if the foreign body is withdrawn, the child may present later with infections including frontal lobe abscess [5].

Non contrasted computed tomography (CT) is the primary neuroimaging modality used in evaluation of NPHI as it is quick and available method. It helps in localization of intracranial foreign bodies and identifications of any other abnormalities like hematoma, contusions, pneumocephalus, depressed fracture, and brain edema. Other neuroimaging modalities like CT angiography (CTA) CT venography (CTV) and MRI used in indicated cases of suspected vascular injury [2]

\section{Patients and Methods}

This is prospective hospital based study includes 6 patients with non missile penetrating head injuries 
admitted and managed at department of neurosurgery and trauma units of Assiut University Hospital through one year from March 2015 to March 2016.

According to our hospital protocol patients were admitted to trauma unit emergency department for resuscitation, stabilization of general condition, supportive care and blood transfusion if needed. History was taken from relatives about age, cause and exact time of trauma. Complete neurological examination was done for all cases including recording of post resuscitation GCS, presence of neurological deficit, pupil reaction and careful examination of wounds Prophylactic antibiotics were given to all our patients mainly third generation cephalosporin in emergency room, Prophylactic antiepileptic was also given to all our patients in form of intravenous phenytoin loading dose then to be continued in maintenance dose for one month.

After stabilization of general condition patients were transported to radiology department for neuroimaging. Our protocol in penetrating brain injuries imaging is to do multislice non contrasted CT scan (bone and soft tissue windows) for all our cases.

Operative data was recorded for each case individually and dural repair type either by simple closure, by using pericranial graft or fascia lata graft. Outcome data was recorded according to Glasgow outcome scale (GOS). Follow-up of all patients during hospital stay and 3 months after hospital discharge.

\section{Results}

Age and sex: Our study include 6 patients 5 of them were males $(83.35 \%)$ and only one female $(16.6 \%)$. The patients ages ranged from 3 to 35 years old with mean age 17 years. 3patients $(50 \%)$ were between $10-30$ years, 2 patients $(33.3 \%)$ were below 10 and only one patient above 30 Fig. (1).

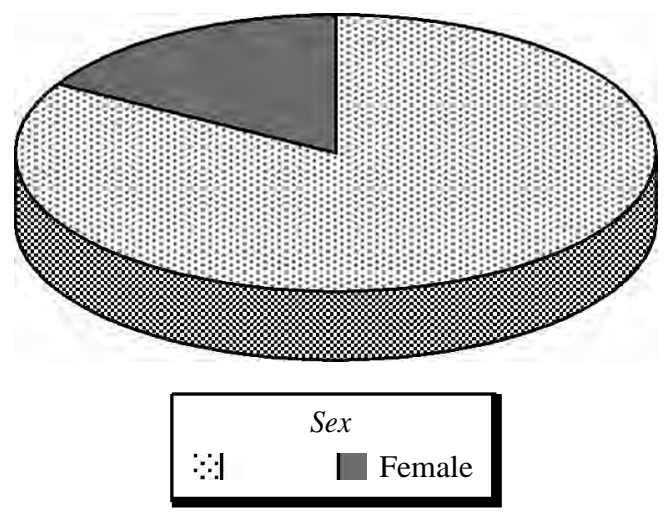

Fig. (1): Sex distrubtion of studied patients.
Mode of injury: Half of cases was assault and accidental in the other half.

Side of injury: $5(83.3 \%)$ cases had injury on left side of skull and only one (16.6\%) patient injury on right side.

Type of penetrating object: 4 (66.6\%) patients was injured by sharp objects and $2(33.3 \%)$ injured by blunt wooden objects.

\section{Clinical presentation:}

Most common clinical presentation was brain matter herniation and cerebrospinal fluid (CSF) leak in $5(83.3 \%)$ patients, followed by decreased level of consciousness in $4(66.6 \%)$ patients and weakness of extremities in $4(66.6 \%)$ patients Table (1).

Table (1): Clinical presentations of penetrated brain injured patients.

\begin{tabular}{lc}
\hline Clinical presentation & Number of cases \\
\hline Brain matter herniation and CSF leak & 5 cases $(83.3 \%)$ \\
Disturbed conscious level & 4 cases $(66.6 \%)$ \\
Neurological deficits & 4 cases $(66.6 \%)$ \\
\hline
\end{tabular}

Site of injury Fronto Parietal lobe injury was noted in $4(66.6 \%)$ patients and temporal lobe injury in $2(33.3 \%)$ patients.

Radiological findings In non-contrast CT brain contusions and lacerations were found in 6 cases $(100 \%)$, intra-axial foreign bodies in 5 cases (83.3). Intra-axial bone fragments were found in 5 cases, while intra-ventricular hemorrhage was found in one patient $(16.6 \%)$.

Surgical management: Surgery was done to all our cases in first 24 hours. Our surgery steps were based on identification of skull fractures and dural defect mainly through craniotomy then removal of accessible bone fragments, foreign objects removal and dural repair. In our study we use pericranial graft in dural repair in all cases with watertight closure, we never use synthetic dural graft.

Post operative Complications two cases (33.3\%) developed seizures and one of them died from status epilepticus post operatively.

Outcome one patient died during the hospital stay after postoperative status epilepticus. Two patients were discharged in GOS-4, and 3 in GOS5. 


\section{Case presentation:}

Male child 7 years old presented after heavy object trauma (Wood falling from height over his skull vault). On examination patient was GCS 14 agitated with apparent left upper limb paresis. He had large right parietal wound with brain matter herniating from it and wooden object penetrating skull vault (Fig. 2).

After stabilization of general condition, emergency MSCT brain was done to the patient which showed right frontoparietal depressed skull fracture with hypodense object (wood) inside the right parietal lobe and underlying contusion (Fig. 3).

Emergency surgery was done to the patient in steps after complete exposure of the depressed segment, removal of the wooden object and bone fragments was done followed by dural repair with pericranial graft and reposition of bone. Post operative patient regained his conscious level (GCS 15) with left upper limb weakness grade four.
Follow-up CT shows complete removal of the wooden object with residual intra-axial bone fragment (Fig. 4).

Patient was referred for physiotherapy and after 3 months follow-up patient was GCS 15 and full motor power.

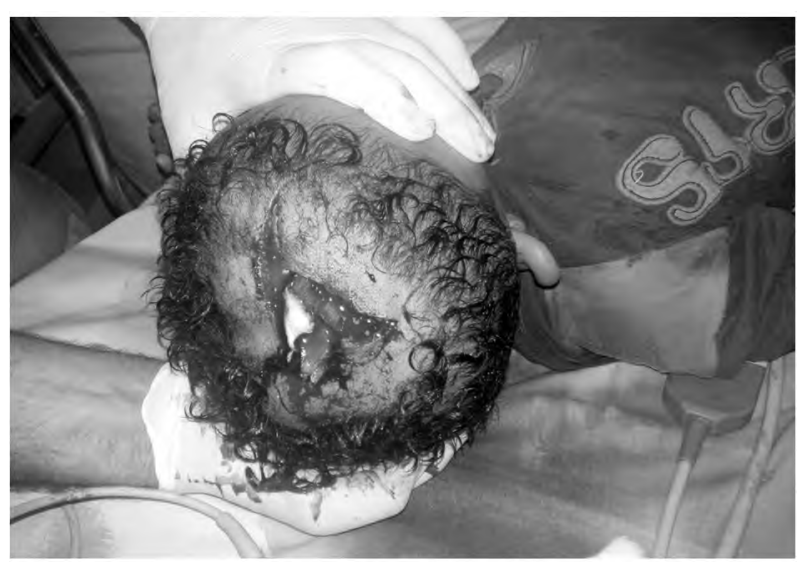

Fig. (2): Achild with non missile (wood) penetrating his skull vault.
(A)

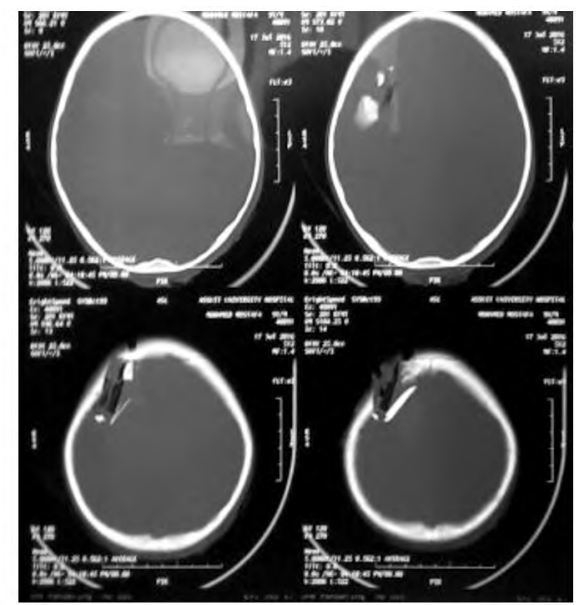

(B)

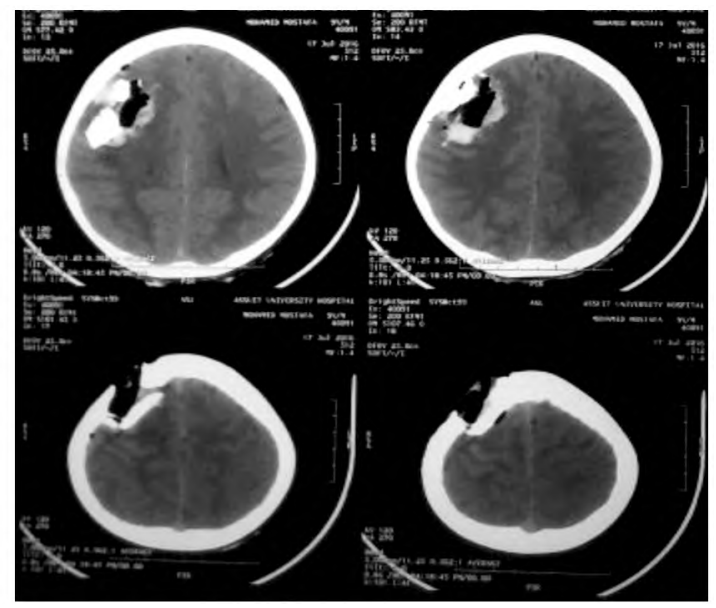

Fig. (3): CT bone and soft tissue window shows right frontoparietal depressed fracture with hypodense foreign object intra-axial.

(A)

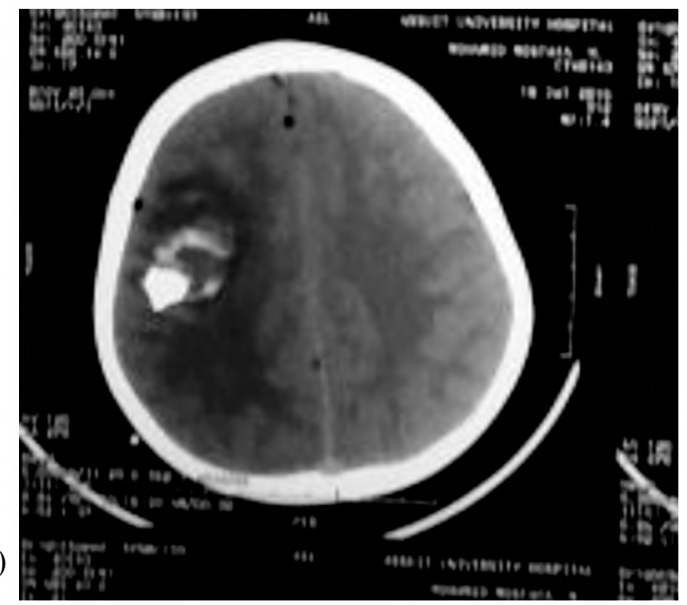

(B)

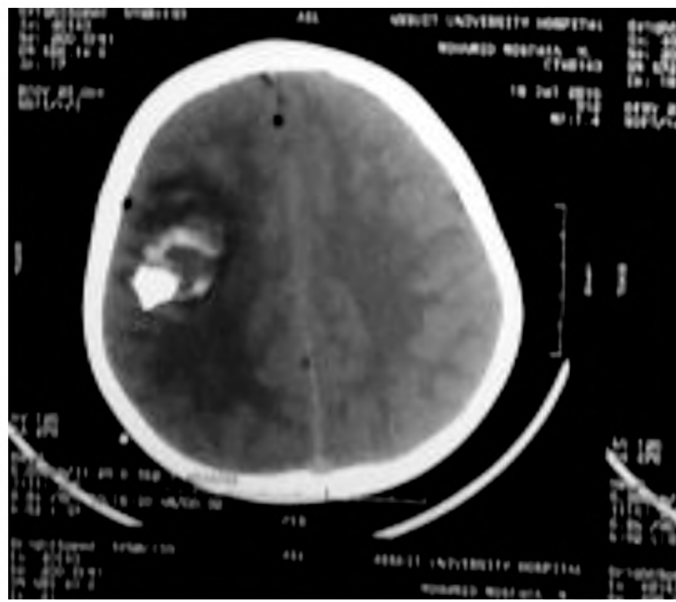

Fig. (4): CT soft tissue window shows complete removal of the wooden object with residual unaccessable bone fragement. 
Case 2:

Male patient 20 years old presented after assault by a sharp heavy object by disturbed conscious level that was removed before presentation.

On examination patient was GCS 14 aphasic with right side hemiparesis grade one and right facial nerve palsy.

MSCT brain shows left frontal depressed frac-

(A)

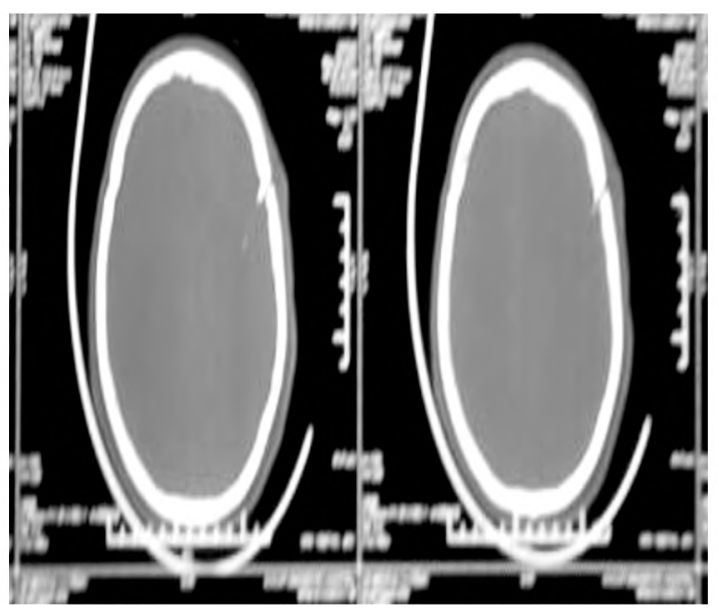

ture, left frontal contusion, subarachanoid hemorrhage and intraventricular hemorrhage (Fig. 5).

Surgery was done to the patient with dural repair by pericranial graft post operative patient GCS 15 dysphasic with right side hemi grade one.

On follow-up after 3 months patient improved to be GCS 15 and improved right side hemi to grade four Fig. (6).

(B)

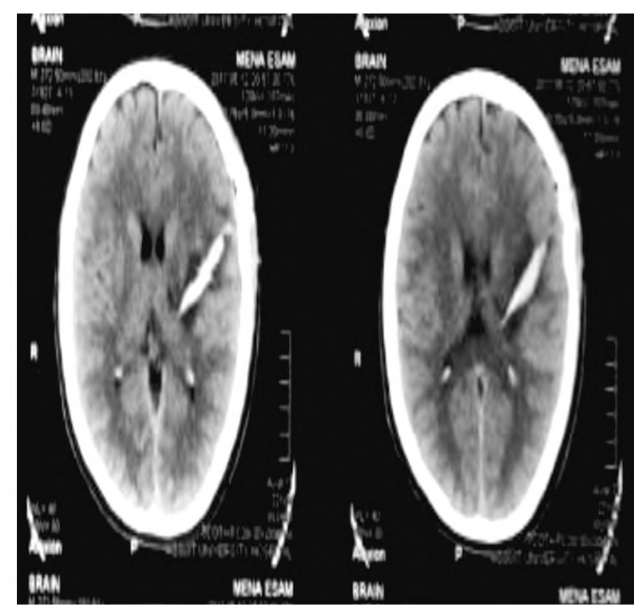

Fig. (5): CT brain shows left frontal fracture with intra-axial contusions along the object trajectory.

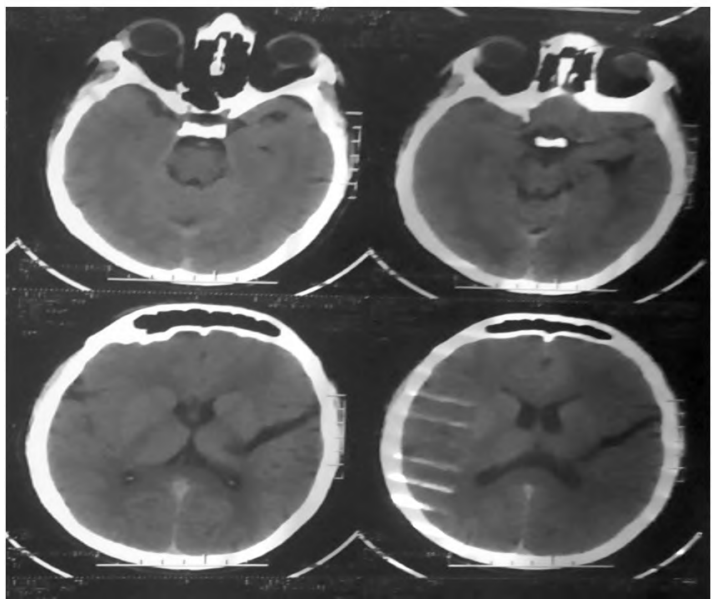

Fig. (6): Follow-up CT shows hypodense arrow along the old trajectory site in left parietal region.

\section{Discussion}

Penetrating brain injuries occur more frequently in young aged males, in our study male to female ratio ( 5 to 1 ) and that nearly the same ratio by previous studies that recorded male to female ratio (4 to 1) [6], also we reported maximum incidence of these injuries in children and young adults below 30 years the same age groups in previous studies which shows maximum age between 11 to 30 [6] we found that half cases is assault and the other half is accidental nearly the same ratio recorded by Kataria et al., [7] in which authors recorded accidental cause in more than half of cases.

Previous studies concluded postoperative CSF leakage in non missile injuries is a rare complication. The low incidence is clearly related to careful and watertight suture of the disrupted dura mater [8] we recorded zero percentage of postoperative CSF leak, also we reported zero percentage of postoperative infections the same reported in previous study by [7] .

Posttraumatic epilepsy is another complication which affects outcome. Kazim et al., [9] recorded $30 \%$ to $50 \%$ of patients with PBI develop seizures due to direct traumatic injury to the cerebral cortex with subsequent scarring. In our study we found $33.3 \%$ of post traumatic seizures.

In our study we recorded one death after temporal penetrating brain injury and that was after status epilepticus postoperative, Lee et al., [10] also found death occur after temporal stab injury as result of herniation postoperative. Kataria et al., [7] study found $25 \%$ of discharged cases with neurological deficit, in our study the percentage of patients discharged with deficit was 33.3 but one case improved to full motor power after one month of physiotherapy. 


\section{Conclusion:}

Non missile Penetrating head injuries although rare than missile injuries, it represents life-threatening injuries that requires urgent intervention. The impacted foreign object should be removed immediately under direct visualization to guard against serious complications such as meningitis and brain abscess. Surgical intervention should be based on the mechanism and extent of injury, also choosing craniotomy or craniectomy technique should be determined for each case individually.

Temporal lobe injuries although less common than forntoparietal injuries it carries worse prognosis. Prophylactic antibiotics and emergency surgical debridement reduce infections significantly.

\section{References}

1- XI-SHENG LI, JUN YAN, CHANG LIU,YU LUO, XINGSHENG, LIAO LIANG and YU SHAO-WEN XIAO: Nonmissile Penetrating Head Injuries: Surgical Management and Review of the Literature World Neurosurg., 98: 873.e9-873.e25, 2017.

2- ESPOSITO D.P. and WALKER J.P.: Contemporary management of penetrating brain injury. Neurosurg Q, 19: 249-54, 2009.
3- VAN DALLEN J.R. and LIPSCHITZ R.: Stab wounds of the skull. Surg, Neurol., 10: 110-4, 1978.

4- HAWORTH C.S. and DE VILLIERS J.C.: Stab wounds to the temporal fossa. Neurosurgery, 23: 431-5, 1978.

5- BAYSTON R., DE LOUVOIS J., BROWN E.M., et al.: Use of antibiotics in penetrating craniocerebral injuries. "Infection in Neurosurgery" Working Party of British Society for Antimicrobial Chemotherapy. Lancet, 355: 1813-1817, 2000.

6- BAL KRISHNA OJHA, SUNIL SINGH, CHHITIJ SRIVASTAVA, NAGESH CHANDRA, et al.: Outcome of Penetrating Brain Injury in Civilian Practice. Indian J. Neurotrauma, 12: 122-127, 2015.

7- KATARIA R., SINGH D., CHOPRA S. and SINHA V.D.: Low velocity penetrating head injury with impactedforeign bodies in situ. Asian. J. Neurosurg., 6: 39-44, 2011.

8- PEASE M., MARQUEZ Y., TUCHMAN A., MARKARIAN A. and ZADA G.: Diagnosis and surgical management oftraumatic cerebrospinal fluid oculorrhea: Casereport and systematic review of the literature. J. Neurol. Surg. Rep., 74: 57-66, 2013.

9- KAZIM S.F., BHATTI A.U. and GODIL S.S.: Craniocerebral injury by penetration of a T-shaped metallicspanner: A rare presentation. Surg. Neurol. Int., 4: 2, 2013.

10- LEE D.H., SEO B.R. and LIM S.C.: Endoscopic treatment of transnasal intracranial penetrating foreign body. $\mathrm{J}$. Craniofac. Surg., 22: 1800-1801.

\section{طرق العلاج والتدخل الجراحى للإصابات النافذة غير النارية

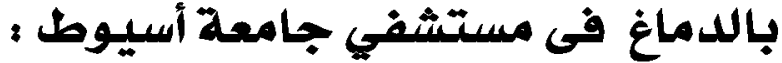 دراسة لمدة عام واحد مامدة أسل}

